\title{
Demographic Observations of Mountain Nyala Tragelaphus Buxtoni in a Controlled Hunting Area, Ethiopia
}

\author{
Paul Evangelista ${ }^{{ }^{*}}$, Nicholas Young ${ }^{1}$, David Swift ${ }^{1}$ and Asrat Wolde ${ }^{1}$ \\ Natural Resource Ecology Laboratory Colorado State University B254 Fort Collins, Colorado \\ *Corresponding author: Paul Evangelista, Natural Resource Ecology Laboratory Colorado State University B254 Fort Collins, Colorado, Tel: (970) 491-2302; E-mail: \\ Paul.Evangelista@ColoState.edu
}

Received date: December 4, 2014; Accepted date: January 30, 2015; Published date: February 6, 2015

Copyright: () 2015 Evangelista P. This is an open-access article distributed under the terms of the Creative Commons Attribution License, which permits unrestricted use, distribution, and reproduction in any medium, provided the original author and source are credited.

\begin{abstract}
The highlands of Ethiopia are inhabited by the culturally and economically significant mountain nyala Tragelaphus buxtoni, an endemic spiral horned antelope. The natural range of this species has become highly fragmented with increasing anthropogenic pressures; driving land conversion in areas previously considered critical mountain nyala habitat. Therefore, baseline demographic data on this species throughout its existing range are needed. Previous studies on mountain nyala demographics have primarily focused on a confined portion of its known range where trophy hunting is not practiced. Our objectives were to estimate group size, proportion of females, age class proportions, and calf and juvenile productivity for a sub-population of mountain nyala where trophy hunting is permitted and compare our results to recent and historical observations. We collected four years of demographic data using direct point counts in a controlled hunting area and summarized the data using the $\mathrm{R}$ statistical software. Our results show that estimated proportion of females $(0.63 ; 0.56-0.69)$ was similar to recent studies of non-hunted populations, but group size $(3.74 ; 3.34-4.13)$, juvenile productivity $(0.47 ; 0.35-0.62)$ and age class proportions (calves: 0.17 juveniles: 0.19 adults: 0.64 ) were considerably different. Our results are more similar to historical accounts than those in a national park. We demonstrate that the mountain nyala's population structure and health varies across its range and may relate to the different management strategies and policies. We recommend using similar methods for remaining under surveyed sub-populations of mountain nyala to inform conservation actions at the landscape scale.
\end{abstract}

Keywords: Conservation; Demography; Endangered; Population structure; Trophy hunting; Wildlife management

\section{Introduction}

The mountain nyala Tragelaphus buxtoni is an endangered antelope endemic to Ethiopia's southern highlands. This culturally and economically valued species is largely found in the Bale Mountains, one of the few remaining forested landscapes in Ethiopia where people and wildlife continue to co-exist. The mountain nyala was not known to western science until 1911 [1] and its extensive range within the Bale Mountains were only confirmed in 1963 [2]. By the early 1970s, Bale Mountains National Park (BMNP) was established to protect the mountain nyala and the region's unusually high concentration of endemic flora and fauna [3]. Since 2000, several additional mountain nyala populations have been identified throughout the Bale Mountains indicating that both its population and range was larger than previously thought $[4,5]$. However, human populations in Ethiopia and the Bale Mountains are accelerating at extraordinary rates, and the reduction and degradation of the mountain nyala's habitats is evident [6-8]. Although new studies of the mountain nyala are emerging, there remain large information gaps that restrict implementation of effective management and conservation strategies. Recent studies have largely focused on needed landscape-level analyses related to population, geographic range, available habitat and human impacts $[5,8,9]$. Only a few demographic studies have been conducted for the mountain nyala; the first over 45 years ago [2], and two recently in a small isolated population in BMNP $[10,11]$. To successfully manage and conserve any wildlife species, a basic understanding of the population's structure and group dynamics are required [12-15]. Demographic parameters (i.e., vital rates) are often used as indices of population's health and stability, and to evaluate a species' status and viability $[16,17]$. These are commonly assessed using population models (e.g., VORTEX, RAMAS, ALEX) which rely on demographic data, such as sex ratio, fecundity, productivity, age structure, group size, and survival rate, to make temporal predictions [18,19]. Gathering demographic information on mountain nyala in its preferred habitats can be a daunting task. The elusiveness of the species is well documented by early trophy hunters and museum collectors $[20,21]$ and its partiality for rugged terrain and dense vegetation prohibits most standard observation methods such as mark-recapture. The first formal study of the mountain nyala, and arguably the most comprehensive, was conducted by Leslie Brown who explored the Bale Mountains in November, 1963, and February and March, 1966 [2]. In addition to mapping mountain nyala range, and estimating density and population, Brown made detailed demographic observations that included gender, age-class and group size. During these years, the Bale Mountains had considerably fewer people and livestock than today and from Brown's description, mountain nyala populations and available habitat were largely undisturbed by humans. His observations led him to believe that there was no immediate threat to the species [2], and the mountain nyala was removed from the International Union's for Conservation of Nature (IUCN) list of endangered species from 1969 to 1975 based on Brown's observations.

Brown's records are a valuable resource, and could potentially serve as a demographic baseline for monitoring current mountain nyala populations. His observations may be particularly useful in identifying 
a sub-population's response to different management and conservation strategies. In particular, recent demographic studies on mountain nyala by Mamo et al. (2010) occurred in a small, but wellknown area in the northern section of BMNP. The area includes the Gaysay Valley and the adjacent Adelay forests (hereafter referred to as Gaysay), and a fenced enclosure that surrounds the park headquarters. Gaysay is transected by a major road and is situated adjacent to the town of Dinsho that was reported to have about 3,600 people in 2005 [22]. While this is an important conservation area for the mountain nyala, Gaysay and the park headquarters covers only $34 \mathrm{~km} 2$ and 1.2 $\mathrm{km} 2$, respectively, and are surrounded by settlements and agriculture. Together, they harbor about 900 mountain nyala $[9,11]$. Both areas are popular with tourists and researchers because mountain nyala and other wildlife can be easily viewed and are habituated to people, livestock and vehicles. However, there is mounting concern that the carrying capacity of Gaysay and park headquarters has reached a dangerous threshold and conditions are having adverse effects on the local mountain nyala populations. Counts conducted by Mamo et al. (2010) found that mountain nyala density in Gaysay was $21 / \mathrm{km} 2$ and $129 / \mathrm{km} 2$ at the park headquarters. Although these numbers are alarmingly high when compared to Brown's estimates $\left(1.5 / \mathrm{km}^{2}\right.$ to $6.9 / \mathrm{km}^{2}$ ) they are supported by other studies $[4,10]$. The high density of mountain nyala and confinement to a small area poses a number of risks including the loss of food resources, reduction in productivity and genetic diversity, and potential transmission of disease [23,25]. Population responses to these and other environmental stressors may be detected through demographic observations, though further investigation may be required to determine exact causes.

Despite its endangered status, limited trophy hunting of mountain nyala is allowed by the Ethiopian government. Although detailed demographic parameters of mountain nyala are not regularly monitored as a management tool, they are commonly used in other countries to assess the impacts of hunting on wildlife populations [13,26-28]. The Bale Mountains have six designated Controlled Hunting Areas (CHA) primarily for trophy hunting of mountain nyala; three have active permits and three remain undeveloped. The CHAs are cooperatively managed by the Ethiopian Wildlife Conservation Authority (EWCA), Oromia Regional government, and a licensed safari outfitter. Hunting activities are intensively managed with strict guidelines and an annual quota for trophy males allocated by EWCA [29]. Every two years, representatives from EWCA estimate the population size of mountain nyala at each concession to determine the annual quota that will be harvested from the area. A sole concession holder (a.k.a. safari outfitter) is granted hunting rights for each CHA with the option of renewing its license every five years as an effort to promote a long-term investment in the area, collaboration with local communities, prevention of unlawful activities, and environmental stewardship. For example, some safari outfitters have set up permanent camps in CHAs hiring local people to maintain facilities and serve as trackers, scouts, guards and other positions. Local communities also receive fund for infrastructure (e.g., schools, roads) from licenses and fees generated through hunting, which help provide incentives for maintaining hunting resources. In theory, this strategy allows EWCA to meet management and conservation objectives; and in most cases, appears to be effective [30]. However, there is a considerable amount of administrative, cultural and natural variability within each $\mathrm{CHA}$ that can directly or indirectly have significant impacts on local mountain nyala populations and their habitats. There are currently no mechanisms in place to assess the effectiveness of hunting regulations and quotas or to detect change in mountain nyala populations.

In this study, we aimed to assess how trophy hunting of mountain nyala affected population demographics over time, and how our observations compared to historic records [2] and more recent studies conducted in BMNP [11]. We collected observational information for four years (excluding one year) which we believe provide a reasonable representation of the group dynamics within the study area. Although the methods used by Brown (1969) and Mamo et al. (2010) differed from ours, we matched the datasets as best we could to improve the accuracy of our comparisons.

\section{Materials and Methods}

\section{Study area}

Our study area was situated within the Abasheba-Demaro CHA located on the eastern flank of the Bale Mountains (Figure 1). Abasheba-Demaro covers an area of $210 \mathrm{~km}^{2}$ with elevations ranging from 1,600 to $2,600 \mathrm{~m}$ a.s.l. The vegetation in the study area consists of two well defined habitat types; the upper afro-montane $(2,300 \mathrm{~m}$ $-3,200 \mathrm{~m})$ and lower afro-montane forest $(1,500 \mathrm{~m}-2300 \mathrm{~m})$. Dominant tree species include Prunus africanus, Albizuia schimperiana, Croton macrostachyus and Scheflera abyssinica. Each of the forested habitat types are interspersed with open areas that offer viewing opportunities. The Abasheba-Demaro CHA is operated by Ethiopian Rift Valley Safaris, the sole concession holder since its establishment in 2002. Mountain nyala are the primary attraction for sport hunters, and EWCA has consistently allocated a harvest quota of five to six trophy bulls each year. Trophy bulls are considered legal for harvest if they have horns exceeding 29 inches in length. If a harvested mountain nyala does not meet minimum horn length, EWCA imposes a fine equal to the cost of the hunting license on concession holder. A permanent camp is staffed by the safari company to help protect the concession from unlawful activities (e.g., poaching) and maintain relationships with local communities. However, human settlements are present just outside the concession and contribute to cattle grazing, wood harvesting, honey gathering, and herb collection that occur within the concession. Still, this area serves as a relatively wellprotected landscape for the mountain nyala and human impact is considered minimal [30]. Recent population surveys for AbashebaDemaro by Atickem et al. (2011) and the EWCA [30] estimated 986 and 975 mountain nyala, respectively, suggesting a density of $4.6 / \mathrm{km}^{2}$. 


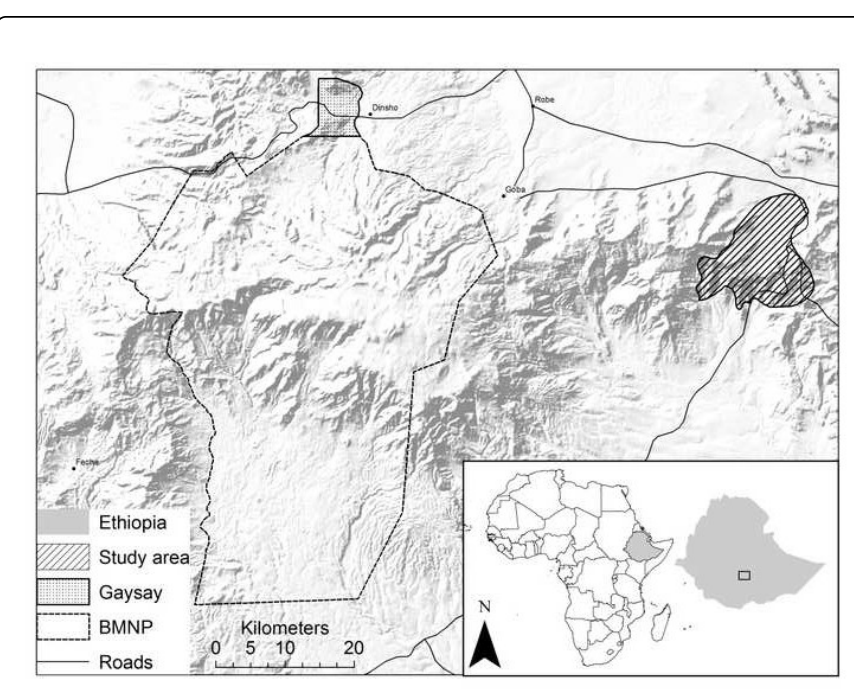

Figure 1: Abasheba-Demaro Controlled Hunting Area and Gaysay Valley located in Bale Mountain National Park (BMNP). The park headquarters are located just southeast of the town of Dinsho

\section{Data collection}

Four years of direct count data were collected between 2006 and 2010 (sampling did not occur in 2008) at two stationary observation points that offered good vantage points. Morning surveys were conducted from a ridge overlooking a basin with an open-canopy forest, while evening surveys focused on the forested edges of a large lowland plain. Surveys occurred at dawn and dusk, each lasting an hour and a half. Four to five trained observers (i.e., authors and local game scouts) participated in each survey using high powered binoculars. Sampling was conducted between January and March each year during 75 surveys. Individual mountain nyala were classified into three age group classes; calves, juveniles and adults, based on body size, coat color, and horn presence and length as described in Evangelista (2007). Calves were considered first year offspring, juveniles in their second year but not yet breeding, and adults are all ages above two years capable of breeding. In addition, the sex of each individual was recorded unless the sex could not be accurately determined in which case the sex was listed as 'unknown'. Individuals were recorded in groups/herds which were used to estimate group size. Groups were defined as individuals that were observed to move together for the entire duration they could be observed.

\section{Statistical analyses}

We used the freely available statistical software $\mathrm{R}$ version 2.14 for our statistical analysis. The data were analyzed for each year separately and pooled together for the four years of the study. We calculated mean, maximum and minimum group size and confidence intervals (CI) using descriptive statistics. To calculate the proportion of females (i.e., sex ratio), age class proportions, and productivity, we used a normal approximation of the binomial response of successes and failures for each estimate (e.g., number of adult females compared to number of adults observed). Only adults were used to estimate the proportion of females due to the difficulty in sexing younger age groups consistently and accurately. Population productivity has been defined in a number of ways depending on the species and purpose
[31]. A total count of individuals was not possible due to the terrain and dense vegetation. Therefore, we define productivity as the proportion of surviving young (calves or juveniles) per adult female mountain nyala. This provides a good estimate of the rate at which new individuals are being added to the population [31]. We calculated productivity using two estimates: the proportion of calves to adult females and the proportion of juveniles to adult females. While using calves provides a better approximation of productivity, detection of calves was likely low as young calves may be kept concealed and adult females traveling with calves may avoid more exposed locations. Therefore, we also include an estimate of productivity using juveniles. While this estimate may be biased low due to first year calf mortalities, juveniles are easier to detect and less likely be concealed. Difficulty in accurately and consistently identifying the sex of calves prevented us from estimating fecundity (number of female calves per number of female adults). To compare sex, age class and productivity proportion estimates among years, we used a Pearson's chi-squared test. We also used this test to compare calf age class proportions to juvenile age class proportions in the following year to provide a measure of calf survival. Since data were not collected for 2008, we limited this test to only years between 2006 to 2007 and 2009 to 2010. Lastly, a Pearson's chisquared test was used to compare productivity estimates using calves versus juveniles. In addition to analyzing our observation data from the Abasheba-Demaro CHA, we replicated our methods using Brown's observation data (1969) from the Bale Mountains during the same months. This allowed for a better comparison of our results with those from 45 years ago.

\section{Results}

A total of 399 individual observations were recorded during the four-year study period from a total of 53 surveys with the most observations occurring in $2006(n=135)$ and the least in $2007(n=37)$. The number of groups observed totaled 147. Survey effort (i) was not equal among years with the largest effort occurring in 2006 ( $i=26$ surveys) and 2009 ( $i=30$ surveys) and the least in 2007 ( $i=9$ surveys) and 2010 ( $i=10$ surveys). Unequal survey effort across years resulted in wider confidence intervals (CI) for estimates in which the survey effort was lower.

\section{Group size}

The mean group size remained relatively constant among years with the total mean group size of 3.74 (95\%CI 3.34-4.13) individuals (Table $1)$. There were no significant differences in group size among years. Group size ranged from single individuals to a maximum of 10 individuals. Both males and females were observed as singletons but males were more than three times more likely to be observed alone than females. Group size was not significantly different between groups that included adult males $(3.7,95 \% \mathrm{CI} 3.3-4.1)$ and those that did not $(3.5,95 \%$ CI 3.0-4.0; $\mathrm{t}=-0.73, \mathrm{df}=144$, $\mathrm{p}$-value $=0.47)$.

\begin{tabular}{|l|l|l|}
\hline Year & Mean Group Size & $\mathbf{9 5 \%} \mathbf{C l}$ \\
\hline 2006 & 3.61 & $(2.89-4.33)$ \\
\hline 2007 & 3.40 & $(2.22-4.58)$ \\
\hline 2009 & 3.82 & $(3.05-4.59)$ \\
\hline 2010 & 3.93 & $(3.13-4.73)$ \\
\hline
\end{tabular}


Citation: Evangelista P, N Young, D Swift, A Wolde (2015) Demographic Observations of Mountain Nyala Tragelaphus Buxtoni in a Controlled Hunting Area, Ethiopia. J Biodivers Endanger Species 3: 145. doi: 10.4172/2332-2543.1000145

Page 4 of 7

\begin{tabular}{|l|l|l}
\hline Total & 3.74 & $(3.34-4.13)$
\end{tabular}

Table 1: Mean size of mountain nyala groups for each surveyed year

\section{Proportion of females}

The mean female proportion pooled for all years of the study was $0.63(95 \%$ CI $0.56-0.69)$ or a $1.7: 1$ female to male ratio (Table 2$)$. The adult female proportion was greatest in 2007 (proportion $=0.76$; sex ratio $=3.17$ females: 1 male) and lowest in both 2009 and 2010 (proportion $=0.60$; sex ratio $=1.52$ females: 1 male). The proportion of females was not significantly different among years $\left(\chi^{2}=0.48, \mathrm{df}=3\right.$, $\mathrm{p}$-value $=0.92$.

\begin{tabular}{|l|l|l|l|}
\hline Year & Sex proportion & (F/M) & $95 \% \mathrm{Cl}$ \\
\hline 2006 & 0.63 & & $(0.52-0.72)$ \\
\hline 2007 & 0.76 & & $(0.54-0.90)$ \\
\hline 2009 & 0.60 & & $(0.47-0.73)$ \\
\hline
\end{tabular}

\begin{tabular}{|l|l|l|l|}
\hline 2010 & 0.60 & & $(0.49-0.71)$ \\
\hline Total & 0.63 & & $(0.56-0.69)$ \\
\hline
\end{tabular}

Table 2: Mean proportion of adult females to adult males for each surveyed year

\section{Age class proportions}

The estimated age class proportions were $17 \%$ (95\%CI 13-21) calves, $19 \%$ (95\%CI 15-23) juveniles and 64\% (95\%CI 59-69) adults (Table 3). When comparing calf proportion to juvenile proportion of the next year, there was no difference between the years 2006-2007 $\left(\chi^{2}\right.$ $=0.006, \mathrm{df}=1, \mathrm{p}$-value $=0.94)$ and between 2009-2010 $\left(\chi^{2}=0.16, \mathrm{df}=\right.$ $1, \mathrm{p}$-value $=0.69)$ suggesting relatively high calf survival rate. There was no difference in age proportions for calves $\left(\chi^{2}=0.71, \mathrm{df}=3\right.$, $\mathrm{p}$ value $=0.87)$, juveniles $\left(\chi^{2}=2.89, \mathrm{df}=3, \mathrm{p}\right.$-value $\left.=0.41\right)$, or adults $\left(\chi^{2}\right.$ $=1.03, \mathrm{df}=3$, $\mathrm{p}$-value $=0.79)$, across years in the study area.

\begin{tabular}{|l|l|l|l|l|l|l|l|l|}
\hline Year & $\begin{array}{l}\text { Mean Proportion } \\
(\%)\end{array}$ & $\mathbf{9 5 \%} \mathbf{C l}$ & $\begin{array}{l}\text { Mean Proportion } \\
(\%)\end{array}$ & $\mathbf{9 5 \%} \mathbf{C l}$ & $\begin{array}{l}\text { Mean Proportion } \\
(\%)\end{array}$ & $\mathbf{9 5 \%} \mathbf{C l}$ \\
\hline 2006 & 15 & $(9-22)$ & 14 & $(9-21)$ & 71 & $(63-78)$ \\
\hline 2007 & 16 & $(7-33)$ & 16 & $(7-33)$ & 68 & $(50-81)$ \\
\hline 2009 & 20 & $(13-29)$ & 20 & $(13-29)$ & 60 & $(50-70)$ \\
\hline 2010 & 17 & $(11-25)$ & 24 & $(17-32)$ & 60 & $(51-68)$ \\
\hline Total & 17 & $(13-21)$ & 19 & $(15-23)$ & 64 & $(59-69)$ \\
\hline
\end{tabular}

Table 3: Mean percent proportion of mountain nyala calves, juveniles, and adults for each surveyed year

\section{Productivity}

The mean productivity across all four years of the study was estimated at $0.42(95 \%$ CI $0.31-0.56)$ calves per adult female (or 42 calves per 100 adult females; Table 4). When estimated using juveniles, the mean productivity was 0.47 (95\%CI 0.35-0.62). Productivity, when estimated using either calves or juveniles, was not significantly different across years (calves: $\chi^{2}=1.19, \mathrm{df}=3, \mathrm{p}$-value $=0.76$; juveniles: $\chi^{2}=2.84, \mathrm{df}=3, \mathrm{p}$-value $=0.41$ ). In addition, there was no significant difference between productivity estimates using calves versus juveniles for a given year. The highest observed productivity using calves was in 2009 (0.54, 0.30-0.98) and the lowest in 2007 (0.32, $0.11-0.84)$. For juveniles, the highest observed productivity was in 2010 (0.66; 95\%CI 0.41-1.06) and the lowest was equal in both 2006 (0.32; 95\%CI 0.18-0.54) and 2007 (0.32; 95\%CI 0.11-0.84).

\begin{tabular}{|l|l|l|l|l|}
\hline \multirow{2}{*}{ Year } & \multicolumn{2}{|l|}{ Calves } & \multicolumn{2}{l|}{ Juveniles } \\
\cline { 2 - 5 } & \multicolumn{2}{|l|}{ Productivity and 95\% Cl } & \multicolumn{2}{l|}{ Productivity and 95\% Cl } \\
\hline 2006 & 0.33 & $(0.19-0.57)$ & 0.32 & $(0.18-0.54)$ \\
\hline 2007 & 0.32 & $(0.11-0.84)$ & 0.32 & $(0.11-0.84)$ \\
\hline 2009 & 0.54 & $(0.30-0.98)$ & 0.54 & $(0.30-0.98)$ \\
\hline 2010 & 0.47 & $(0.27-0.80)$ & 0.66 & $(0.41-1.06)$ \\
\hline
\end{tabular}

\begin{tabular}{|l|l|l|l|l|}
\hline Total & 0.42 & $(0.31-0.56)$ & 0.47 & $(0.35-0.62)$ \\
\hline
\end{tabular}

Table 4: Mountain nyala productivity (number of calves or juveniles per adult female) for both calves and juveniles for each surveyed year

\section{Discussion}

Our estimates of group size differ from more recent estimates in Gaysay and the park headquarters but are similar to historical accounts. We observed a group size of 3.7 individuals which is less than half that of the estimates found by Refera and Bekele (2004) and Mamo et al. (2010) which estimated group size in Gaysay and the park headquarters between 7.9-10.2 individuals and 7-12 individuals, respectively. Historical accounts of group size in Gaysay were estimated at an average of 5.6 individuals [2] and groups were rarely observed with more than 12 individuals with most group sizes between 4-12 individuals [32]. Hillman (1986) reported observing mountain nyala groups of up to 95 individuals in 1985; however details of this report are absent. Our estimates of group sizes ranging from 1 to 10 individuals agree with the majority of the historical observations across the mountain nyala's range.

While our findings on group size are consistent with historical accounts, herd structure and herd size can fluctuate widely within a year as a result of seasonal (e.g., rainy season versus dry season) and social (e.g., rutting season, calving season) influences [34,35]. Our 
observations in the Abasheba-Demaro study area were restricted to the dry season. Although fluctuation in herd size due to seasonal variation has been observed for a related species to the mountain nyala (e.g., Kudu) [36], Mamo et al. (2010) conducted surveys in both the rainy and dry seasons and did not find significant differences in group size between the two seasons for Gaysay and the park headquarters. It is also important to consider the undocumented differences in how a group is defined from study to study which may lead to discrepancies in group size estimates.

Our results indicate relatively high rates of mountain nyala productivity in the Abasheba-Demaro study area even with annual removal of individuals from trophy hunting (Table 4). These estimates are higher than those reported in Gaysay and park headquarters. Mamo et al. (2010) described productivity estimates for calves to be 0.08 and 0.09 for Gaysay and the park headquarters, respectively. These estimates are over three times lower than the estimates we observed in the Abasheba-Demaro CHA (0.42; Table 4). For juveniles, when calculated by combining both adult females and sub-adult females, Mamo et al. (2010) show productivity to be 0.19 and 0.17 for Gaysay and the park headquarters, respectively. Our estimates of productivity in the Abasheba-Demaro study area are closer to historical records from Brown (1968) who estimated productivity across the Bale Mountains between 0.25 - 0.33 calves/adult female. Brown (1968) also observed higher productivity during the calving season although the exact calving time period and duration of mountain nyala is still uncertain and is likely to vary spatially $[4,11]$.

The majority of previous studies on mountain nyala found the sex ratio of females to males to be near 2:1 [2,10,11]. Our estimate of adult sex ratio, while slightly lower, agrees with these reports (1.7:1 or 0.63 as a proportion). These estimates are similar to those reported for hunted populations of the closely related kudu (1.67 females: 1 male) [35]. As with group size, sex ratio in mountain nyala has been observed to fluctuate throughout the year based on breeding and rutting seasons. For example, Brown (1968) observed an adult female to male sex ratio 4.06:1 (95\%CI 2.72-6.10:1) in the Bale Mountains during the rutting season from November to December. Although we consider our sex ratio estimates an accurate representation of the population, it's important to consider that direct counts of individuals may lead to a count that is biased low for males because males are generally more secretive and harder to observe.

Our age class proportion estimates showed more calves and juveniles than those reported in Gaysay and the park headquarters. Mamo et al. (2010) used population counts (at the park headquarters) and line transects to survey mountain nyala population in Gaysay and the park headquarters. They found $5 \%$ of the population consisted of calves, $10 \%$ were juveniles, and $81 \%$ were adults and sub adults in Gaysay with similar age class proportions for the park headquarters ( $5 \%$ calves, $8 \%$ juveniles, and $85 \%$ adults). Of the 252 mountain nyala Brown confidently identified from both expeditions, 37 (14.7\%) were males, 170 (67.8\%) were females, and 44 (17.3\%) were calves (juveniles were not distinguished) [2]. If we examine his observations from the Bale Mountains separating his data by expedition dates and season, more distinct patterns emerge. In November, 1963, Brown confidently identified 50 mountain nyala; 4 (8\%) males, 41 (82\%) females and 4 (8\%) calves. In February and March of 1966, Brown's expedition identified 192 mountain nyala; 32 (16.7\%) adult males, 130 (67.7\%) adult females and 20 (15.6\%) calves (Brown, 1969). The increased number of observed males and calves in 1966 may be attributed to the time of year the surveys were conducted. It is believed that mountain nyala will mate or calve throughout the year, but are generally synchronized to one or two periods of the year. Evangelista et al. (2007) observed that the calving period for mountain nyala in the Bale Mountains peaks in mid- October following the rainy season. By November, calves may still be in hiding or not yet born resulting in a smaller number of observations. By February and March, calves are noticeably more abundant, highly mobile, and of comparable size [4]. Similarly, adult males are less conspicuous in November than they are in February and March. Adult males are solitary throughout most of the year or found in small bachelor groups. In January, they become more gregarious as females approach estrus and males compete for mating access [4]. In our study area, calves and juveniles together accounted for about $37 \%$ of the total population. Although the mean juvenile proportion was larger for each year, it was not significantly different from the calf proportion of the previous year for years 2006-2007 and 2008-2009 suggesting that calf survival is high in our study area or that calves are extraordinarily hard to detect. Although there were no significant differences between years for juvenile proportions, juvenile survival is likely to vary from year to year as a result of environmental fluctuations [37].

When surveying large mammal populations, the time of year sampling is conducted is important. While it would be preferable to include surveys performed at all seasons to track annual changes in demographics, we are confident that our results provide robust demographic estimates of the population in Abasheba-Demaro study area. This is further supported by the fact that no differences in demographic parameters between seasons were found in Gaysay [11]. That said, sexing and aging mountain nyala can be difficult over long distance and in dense vegetation cover which further highlights the need for detection probabilities to be included in future studies.

Given the habitat and behavior of mountain nyala, the use of direct observational counts was a successful method in our study area to obtain the data required for demographic analysis. Although the forest vegetation and terrain can limit visibility and detection of individuals, we were able to find locations that provided visual access to large areas where mountain nyala could be observed and confidently classified. Unlike the population of mountain nyala in Gaysay and the park headquarters, the mountain nyala in the Abasheba-Demaro study area are much less habituated to human presence and are more cryptic. Therefore, mark-recapture and transect surveys were not feasible and using observation locations that limit disturbance were important to the collection of data. The direct observational count method can provide robust estimates of demographic parameters with relatively limited monetary and personnel resources in a short amount of time. This method could be especially useful for surveying multiple populations in a quick and consistent fashion. Future survey efforts would further benefit from incorporating detection probabilities for different observers, habitats, age classes and sex $[38,39]$.

\section{Conclusion}

Our demography estimates in the Abasheba-Demaro controlled hunting area provide the most comprehensive indices of the health of a hunted mountain nyala population to date. The population has a high productivity rate with high proportions of calves and juveniles and an apparent high survival rate of calves to juveniles. This area holds a high proportion of males with large, record setting bulls continuing to be harvested suggest a healthy male population that has likely not experienced any body-size or horn size impacts from the annual size-selective harvesting [40]; however, future studies aimed at 
these questions specifically would be beneficial. While the populations in Gaysay and the park headquarters are not hunted, their densities are at levels that likely to be unhealthy and unsustainable $[11,33]$. This will be further compounded by the rapid development and expansion of the nearby town of Dinsho and the completion of a newly paved road connecting it to the village of Robe to the East and the town of Shashemene to the West.

The status of the Abasheba-Demaro population is likely due to the intensive hunting policies and regulations in place for mountain nyala and the management strategies of the concession owners. Although this area is outside the national park, it is still patrolled and managed year round under the direction of the concession owner. This appears to help protect the area from sprawling land conversion and increasing presence of humans and livestock; both implicated for declines in mountain nyala densities and range $[4,6,7,9]$. There is an economic incentive for the concession owners to protect and promote the health of the mountain nyala population in this area. If the population falls and can be detected through bi-annual surveys conducted by the EWCA, the concession will be allocated a lower harvest quota reducing the number of available hunts and ultimately the concession owner's revenue. Without the full quota, the concession owner may not be able to sustain the business and may have to abandon their year round presence. Without their direct and continual oversight, the area would likely be quickly settled, grazed and over-harvested for resources by nearby communities with potential cascading negative impacts on the mountain nyala status in the area. Large mammal conservation over large spatial extents is becoming more and more difficult as habitat fragmentation continues subsequent to human population growth [41]. As the mountain nyala population continues to become fragmented, all populations within their geographic range need to be monitored and evaluated. Understanding and managing sub-populations can improve conservation at broad-scales [42]. While our study provides new insights into a largely unstudied but critical sub-population of mountain nyala, additional areas need to be surveyed to gain a more complete understanding of the total population's health. Specifically, areas of the Harenna forest in the southern portion of Bale Mountains National Park need a comprehensive evaluation of mountain nyala. The methods employed in this study could be used to survey these additional areas using relatively few resources. Future conservation and status evaluation efforts would greatly benefit from delineating and evaluating subpopulations of mountain nyala across its existing range.

\section{Acknowledgements}

The authors would like to thank The Murulle Foundation, Ethiopian Rift Valley Safaris for their logistics and data collection support, and the Ethiopian Wildlife Conservation Authority for their cooperation. In addition, the authors are thankful for the guidance and expertise from the scientists at the Natural Resource Ecology Laboratory at Colorado State University.

\section{References}

1. Lydekker R (1911) On the mountain nyala, Tragelaphus buxtoni. Proc Zool Soc Lond 81: 348-353.

2. Brown LH (1969) Observations on the status, habitat and behavior of the mountain nyala Tragelaphus buxtoni in Ethiopia. Mammalia 33: 545-597.

3. Waltermire R (1975) A National Park in the Bale Mountains. Walia 6: 20-23.
4. Evangelista PH, Swartzinski P, Waltermire R (2007) A profile of the mountain nyala (Tragelaphus buxtoni). African Indaba- Special Report 5: 1-48.

5. Evangelista PH, Norman J, Berhanu L, Kumar S, Alley N (2008) Predicting habitat suitability for the endemic mountain nyala (Tragelaphus buxtoni) in Ethiopia. Wildl Res 35: 409-416.

6. Stephens PA, d'Sa CA, Sillero-Zubiri C, Leader-Williams N (2001) Impact of livestock and settlement on the large mammalian wildlife of the Bale Mountains National Park, southern Ethiopia. Biol Conserv 100: 307-322.

7. Mamo Y, Bekele A (2011) Human and livestock encroachment into the habitat of mountain nyala (Tragelaphus buxtoni) in the Bale Mountains National Park, Ethiopia. Trop Ecol 52: 265-273.

8. Evangelista PH, Norman J, Swartzinski P, Young NE (2012) Assessing habitat quality of the mountain nyala Tragelaphus buxtoni in the Bale Mountains, Ethiopia. Curr Zool 58: 525-535.

9. Atickem A, Loe LE, Langangen, Rueness EK, Bekele A et al. (2011) Estimating population size and habitat suitability for mountain nyala in areas of different protection status. Anim Conserv 14: 409-418.

10. Refera B, Bekele A (2004) Population status and structure of mountain nyala in the Bale Mountains National Park, Ethiopia. Afr J Ecol 42: 1-7.

11. Mamo Y, Pinard MA, Bekele A (2010) Demography and dynamics of mountain nyala Tragelaphus buxtoni in the Bale Mountains National Park, Ethiopia. Curr Zool 56: 660-669.

12. Hebblewhite M, Percy M, Serrouya R (2003) Black bear (Ursus americanus) survival and demography in the Bow Valley of Banff National Park, Alberta. Biol Conserv 112: 415-425.

13. Taylor MK, Laake J, McLoughlin PD, Born EW, Cluff HD et al. (2005) Demography and viability of a hunted population of polar bears. Arctic 58: 203-214.

14. Bender LC (2006) Uses of herd composition and age ratios in ungulate management. Wildl Soc Bull 34: 1225-1230.

15. Mech LD (2006) Estimated age structure of wolves in Northeastern Minnesota. J Wildl Manage 70: 1481-1483.

16. Beissinger SR, Westphal MI (1998) On the use of demographic models of population viability in endangered species management. J Wildl Manage 62: 821-841.

17. Brook BW, Cannon JR, Lacy RC, Mirande C, Frankham R (1999) Comparison of the population viability analysis packages GAPPS, INMAT, RAMAS and VORTEX for the whooping crane (Grus americana). Anim Conserv 2: 23-31.

18. Lande R, Orzack SH (1988) Extinction dynamics of age-structured populations in a fluctuating environment. Proc Natl Acad Sci USA 85: 7418-7421.

19. Lindenmayer DB, Lacy RC, Pope ML (2000) Testing a simulation model for population viability analysis. Ecol Appl 10: 580-597.

20. Sanford G, LeGendre S (1930) In quest of the queen of Sheba's antelope. Nat Hist 30: 161-176.

21. Baum JE, (1935) Unknown Ethiopia. Grosset and Dunlap Publishers. New York, USA.

22. Anonymous (2005) The Central Statistical Agency of Ethiopia.

23. Newmark WD (1991) Tropical forest fragmentation and the local extinction of understory birds in Eastern Usambara Mountains, Tanzania. Conserv Biol 5: 67-78.

24. McCallum H, Dobson A (2002) Disease, habitat fragmentation and conservation. Proc Biol Sci 269: 2041-2049.

25. Keller BJ, Bender LC (2007) Bighorn sheep response to road-related disturbances in Rocky Mountain National Park, Colorado. J Wildl Manage 71: 2329-2337.

26. Caro TM (1999) Demography and behavior of African mammals subject to exploitation. Biol Conserv 91: 91-97.

27. Cooley HS, Wielgus RB, Koehler GM, Robinson HS, Maletzke BT (2009) Does hunting regulate cougar populations? A test of the compensatory mortality hypothesis. Ecology 90: 2913-2921. 
Citation: Evangelista P, N Young, D Swift, A Wolde (2015) Demographic Observations of Mountain Nyala Tragelaphus Buxtoni in a Controlled Hunting Area, Ethiopia. J Biodivers Endanger Species 3: 145. doi: 10.4172/2332-2543.1000145

Page 7 of 7

28. Mockrin MH (2009) Duiker demography and dispersal under hunting in Northern Congo. Afr J Ecol 48: 239-247.

29. Wildlife Development, Conservation and Utilization Council of Ministers Regulation (2008) Addis Ababa: Federal Negarit Gazeta of the Federal Democratic Republic of Ethiopia.

30. Ewnetu M, Wami K, Zwude C, Mengistu A (2009) A report on wildlife census of Abasheba-Demero Controlled Hunting Area. Addis Ababa, Ethiopia: Ethiopian Wildlife Conservation Authority.

31. Skalski JR, Ryding KE, Millspaugh JJ (2005) Wildlife Demography. Elsevier Inc.

32. Maydon HC (1925) Simen. Its Heights and Abysses. London, U.K.

33. Hillman JC (1986) Conservation in the Bale Mountains National Park, Ethiopia. Oryx 20: 89-94.

34. Simpson CD (1968) Reproduction and population structure in greater kudu in Rhodesia. J Wildl Manage 32: 149-161.

35. Annighöfer PS, Schütz S (2011) Observations on the population structure and behaviour of two differently managed populations of the greater kudu (Tragelaphus strepsiceros) in Namibia. Eur J Wildl Res 57: 895-907.

36. Owen-smith N (1990) Demography of a large herbivore, the greater kudu Tragelaphus strepsiceros, in relation to rainfall. J Anim Ecol 59: 893-913.
37. Gaillard JM, Festa-Bianchet M, Yoccoz NG (1998) Population dynamics of large herbivores: variable recruitment with constant adult survival. Trends Ecol Evol 13: 58-63.

38. Nichols JD, Hines JE, Sauer JR, Fallon FW, Fallon JE et al. (2000) A double-observer approach for estimating detection probability and abundance from point counts. Auk 117: 393-408.

39. Mackenzie DI (2006) Modeling the probability of resource use: the effect of, and dealing with, detecting a species imperfectly. J Wildl Manage 70: 367-374.

40. Fenberg PB, Roy K (2008) Ecological and evolutionary consequences of size-selective harvesting: how much do we know? Mol Ecol 17: 209-220.

41. Hodgson JA, Moilanen A, Wintle BA, Thomas CD (2011) Habitat area quality and connectivity: striking the balance for efficient conservation. J Appl Ecol 48: 148-152.

42. Stoner DC, Wolfe ML, Choate DM (2006) Cougar exploitation levels in Utah: implications for demographic structure, population recovery, and metapopulation dynamics. J Wildl Manage 70: 1588- 1600. 